\title{
MACROFUNGI OF PULAU BIDONG
}

TSIA MUN KAIK AND AQILAH MOHAMMAD*

\author{
School of Marine and Environmental Sciences, Universiti Malaysia Terengganu, \\ 21030 Kuala Nerus, Terengganu.
}

"Corresponding author: aqilahmohammad@umt.edu.my

\begin{abstract}
Studies on fungal taxonomy and fungal diversity are crucial for a better understanding of the interactions between fungi and their habitats. To date, there is no published record on macrofungal diversity in Pulau Bidong, Terengganu. Therefore, this study aimed to identify macrofungi species found with their respective substrates and to determine the macrofungal diversity in the island. The study was conducted at two different occasions and comprised of two trails near Universiti Malaysia Terengganu Research Station in Pulau Bidong, Terengganu. Collection of fresh macrofungi was made and additional data including host information, distinctive features of each fungal sample and several environmental parameters was also recorded. Fresh specimens were later observed and identified before being dried prior to storage. Overall, 65 macrofungal species with 2 unidentified species belonging to 21 families and 34 genera were recorded. Trail A and trail B recorded diversity index of 2.67 and 3.14 for Shannon Index while Simpson index recorded 0.90 and 0.94 respectively. The macrofungal diversity was dominated by family Polyporaceae while rare species discovered were from family of Tricholomataceae, Hericiaceae, Stereaceae, Schizophyllaceae, Sclerodermataceae, Dacrymycetaceae, Tremellaceae, Russulaceae and Clavulinaceae. The most common macrofungal substrates was decayed branches while other macrofungal substrates found were decayed trunks and leaves, soil, termite mounds, and living tree. In conclusion, the macrofungal species were randomly distributed with high diversity in both trails. Therefore, it is recommended that an increase in sampling trips, sampling efforts and areas covered be provided to increase the number of macrofungal species discovered and accuracy of diversity studies in the future.
\end{abstract}

Keywords: macrofungi, diversity, Bidong, Terengganu, Malaysia

\section{Introduction}

There are limited reports on macrofungal diversity on local islands published by local mycologists in Terengganu. One of the studies on macrofungal diversity in island ecosystem in Terengganu was reported by Zainuddin et al. (2010) who recorded 19 families of fungi species identified from Redang Island, Terengganu. They also compared macrofungal diversity from Aur Island, Johor and recorded 14 families. Another recent macrofungal diversity study in Terengganu was reported by Mohammad et al. (2019) who documented 31 macrofungi species belonging to 26 genera, and 14 families in several areas of Tasik Kenyir at different occasions between October 2013 and March 2016. Their findings marked the first report of the macrofungi surveyed in the largest human-made island in the Southeast Asian region.

Similar studies were also documented at different areas within Peninsular Malaysia. Abdullah et al. (2005) who conducted a study of macrofungi in Northeast Langkawi Island revealed that there were a total of 212 specimens collected from eight sites namely Kilim Mangrove Forest, Kisap Mangrove Forest, Pulau Langgun, Pulau Dendang, Sungai Sireh, Durian Perangin, Selat Panchor Forest Reserve and Gunung Raya Forest Reserve from 2003 to 2004. Their studies showed an increase in the number of specimens collected, with additional 114 specimens more than the number of macrofungal species reported earlier by Kuthubutheen (1981), due to the difference in sampling effort and sampling sites in Langkawi Island.

Pulau Bidong is one of the well-known islands within Bidong Archipelago, and once became a home to Vietnamese refugees. The island is covered with secondary forest mainly composed of dipterocarps trees, lowland forest vegetation and rocky areas within coastal forest (Adanan et al., 2016; Pesiu et al., 2016). Pulau Bidong has a great potential to contain various macrofungal species as there are diverse substrates such as twigs, decaying leaves and soil that support the growth of macrofungi. Previously, a short-term study on macrofungi in Pulau Bidong was initiated and reported by Aziz (unpublished, 2014) and Razak (unpublished, 2015) to obtain descriptions and composition of macrofungal species in the island. Aziz (unpublished, 2014) recorded 16 species, followed by Razak in 2015 with 45 species which included all of 16 species found by Aziz (2014) and additional 29 new species. However, the diversity of macrofungi in the island is not yet fully understood. This study therefore aims to document the species of macrofungi occurring in Pulau Bidong and to update the checklist of macrofungal species in the island. 


\section{Materials and Methods}

This study was carried out in Pulau Bidong $\left(5^{\circ} 37^{\prime} \mathrm{N}\right.$, $\left.103^{\circ} 4^{\prime} \mathrm{E}\right)$ which is located off the coast of Terengganu, Peninsular Malaysia (Figure 1). Study areas were visited on the 25th August 2016 and 14th October 2016 where two days and one night were spent on each occasion. Occurrence of macrofungal fruit bodies was observed at two assessable forest trails labelled as trail A and trail B. The first forest trail or trail A (represented by red line) was located near the former Vietnamese refugee camp area near to the sandy beach (Figure 1). This area was exposed to sunlight as it was less shaded by trees. Furthermore, forest litters were scarce at the first few metres of the entry of trail A and the area mostly consisted of rocks on the forest floor (Figure 2A). Meanwhile, the second forest trail or trail B (represented by yellow line) was located behind the dorm of Bidong Island Research Station, further away from the sandy beach (Figure 1). Trail B was accessible with the presence of ropes for hiking along the trail. The trail was thickly wooded and shaded with trees. The starting point for this trail showed moist soil covering huge amount of forest litters including dead leaves, decaying plant materials and living trees (Figure 2B).

Fresh, mature and good condition macrofungi samples were collected from the sites for further examination. Substrates of the specimens were identifed and recorded including their host and their associated host (i.e. living tree). Next, undisturbed sample's colour, colour changes before and after collecting were also recorded for subsequent identification of colour using Flora of British identification chart by Rayner et al. (1969). All data were recorded in a recording sheet and field notes. Photos of fresh samples of macrofungi spotted along the trail were taken before samples were collected. Photographs of fresh specimens were taken in three different angles which were the bottom that displayed the gills and pores of the specimen, the top of the sample which displayed the cap of the specimen and side of the sample that displayed the natural habitat and substrate of the sample (Figure 3A-C). Environmental parameters including temperature, relative humidity and light intensity were measured using appropriate devices and were recorded in field notes. Average temperature and relative humidity were measured using 3 in 1 anemometer Ex-tech 45160. Light intensity was measured using Hanna HI97500 lux meter. Meanwhile, elevation and coordinates of respective locations of macrofungi were recorded using Garmin E-Trex 10/20 Global Positioning System device. A ruler was used to measure the size (height and width) of the samples collected.

Tabulation of data for macrofungi species, macrofungi substrates and coordinates of the macrofungi samples and environmental parameters was done in Microsoft Office Excel and was used for data interpretation. Comparison of sampling effort was made using rarefaction curve plotted using Paleontological Statistics (PAST) and ECOSIM software. Apart from this, SPSS software was used to plot and analyse data collected from sampling trips which included macrofungal species composition and the types of substrates according to macrofungi species. Besides that, the diversity index calculation was made which included species diversity and species evenness of Bidong Island. Shannon Diversity index and Simpson Index of Diversity (Molles, 2013; Cruz, 2015) were used for diversity index calculations.

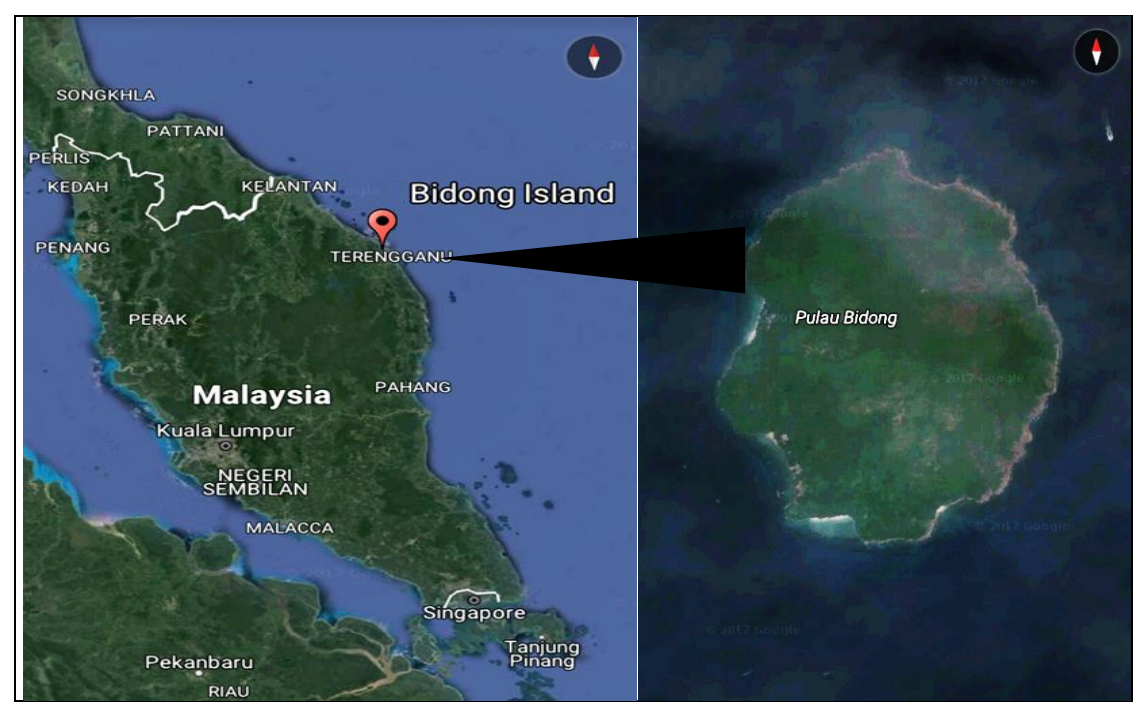

Figure 1: Sampling site in Bidong Island (Source: Google Earth, accessed on 30 ${ }^{\text {th }}$ October 2016 at 5:15 pm and 18 February 2017). 

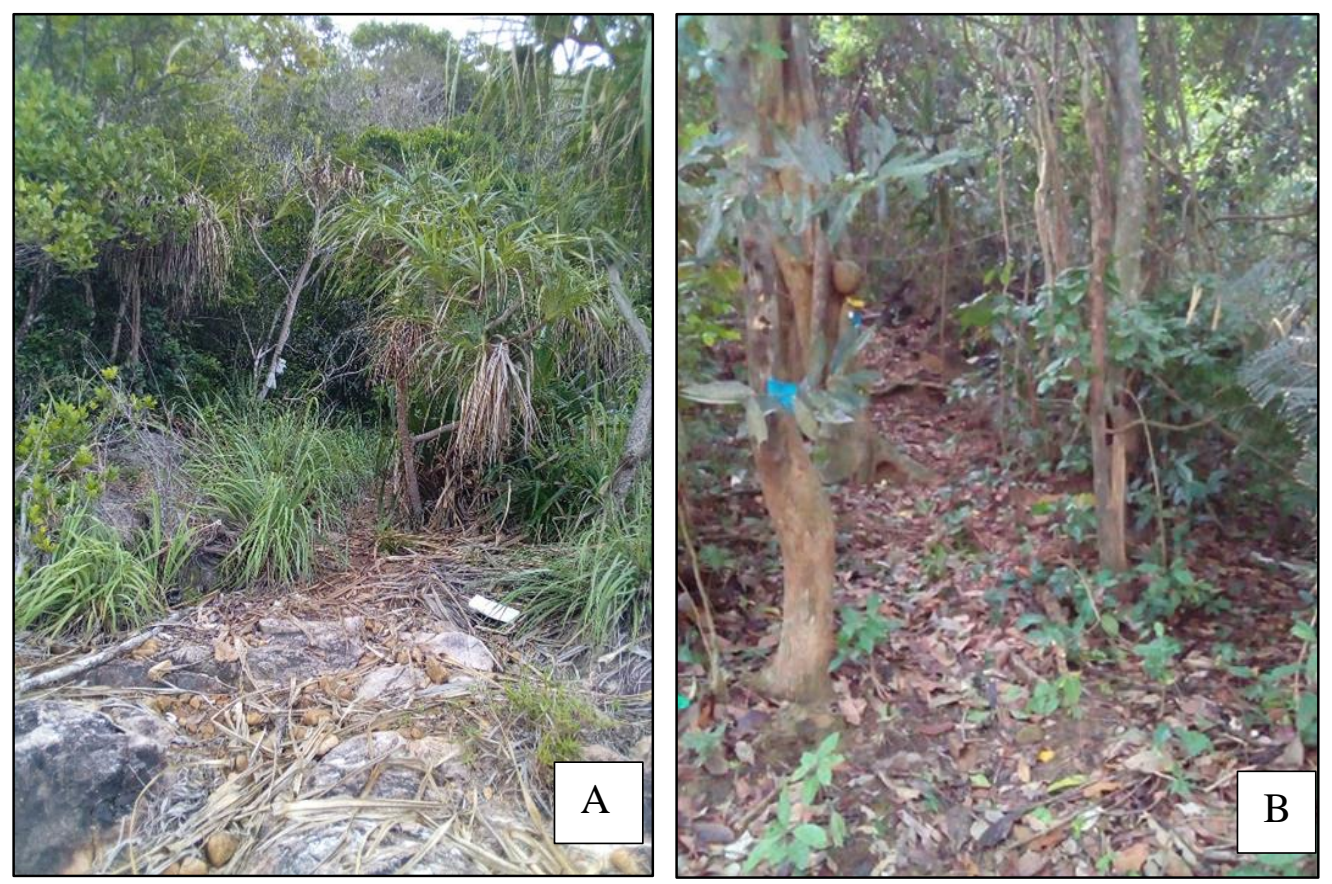

Figure 2: Forest trail in former Vietnamese refugee camp area or trail A (A) and forest trail behind the dorm of UMT Bidong Island Research Station or trail B (B)
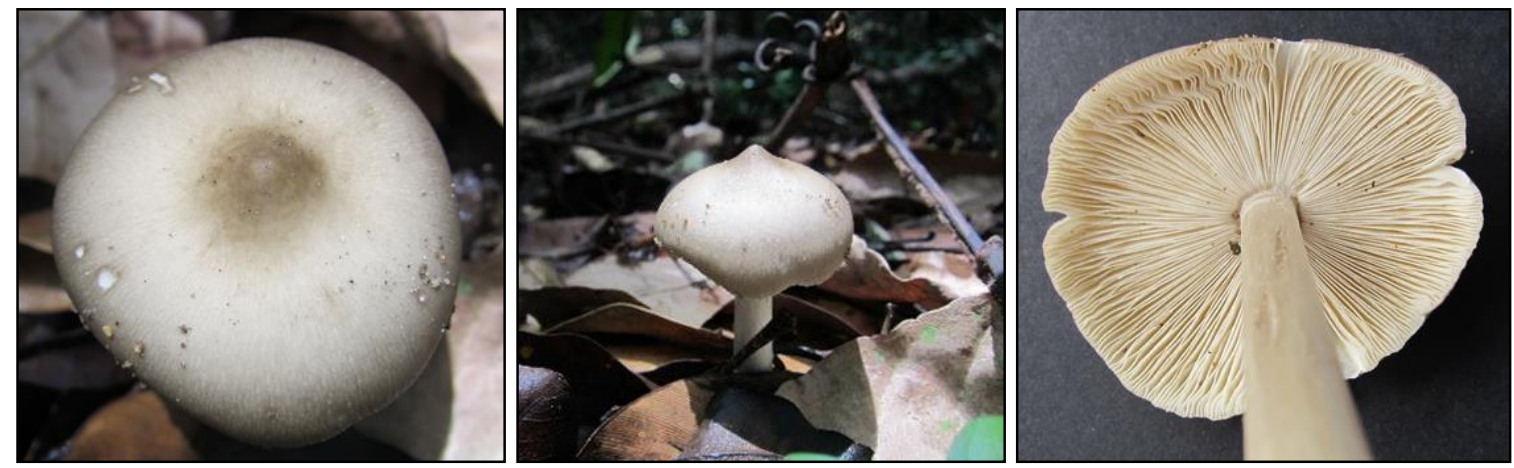

Figure 3: Bottom angle of sample (A), top angle of sample (B) and side angle of sample (C)

\section{Results and Discussion}

The mushroom taxa recorded during the study is enumerated in Table 1. There were a total of 65 macrofungi species collected along two sampling trails in Pulau Bidong on two sampling trips (Table 1). Of all the species found, 63 species could be identified while 2 species could not be identified. Of the 63 species, 20 species were identified until species classification level while 43 species were identified until genus classification level. The 63 macrofungal species belonged to 21 families and 34 genera. Among the 21 families, 20 families were from the phylum Basidiomycota and 1 family was from phylum Ascomycota. The high abundance of Basidiomycota fungi could be due to the unique difference of sporeproducing structures with varied sizes and fruit body structures between species from phylum Basidiomycota and Ascomycota that contributed to the effectiveness of the dispersal. The low effectiveness of spore dispersal decreased the abundance of macrofungi species in an area. Basidiomycota have spore-producing structure on the surface outside the basidia while Ascomycota have asci inside which the spores are stored (Oberwinkler, 2012). The spore's dispersal rate of Ascomycota might be disturbed by the surrounding condition such as rain that causes the spores to be unevenly dispersed in large quantity and this decreased the effectiveness of dispersal in Ascomycota (Kendrick, 2002). This is because the operculum structure of asci absorbed water from the surrounding and could not evenly explode their spores (Staples, 2007). 
Table 1: Collection of macrofungi species from Trail A and Trail B in Pulau Bidong

\begin{tabular}{|c|c|c|}
\hline Macrofungi & Trail A & Trail B \\
\hline \multirow{2}{*}{\multicolumn{3}{|c|}{$\begin{array}{l}\text { ASCOMYCOTA } \\
\text { Order Xylariales } \\
\text { Family Xylariaceae }\end{array}$}} \\
\hline & & \\
\hline Xylaria carpophila (Pers.) Fr. & 14 & - \\
\hline Xylaria hypoxylon (L.) Grev. & - & 2 \\
\hline
\end{tabular}

\section{BASIDIOMYCOTA}

Order Agaricales

Family Agaricaceae

Agaricus sp.

Family Inocybaceae

Crepidotus spp. 2

Family Lepiotaceae

Lepiota $\mathrm{sp.}$

Macrolepiota sp.

Family Lyophyllaceae

Termitomyces microcarpus $\quad 18$

(Berk. \& Broome) R. Heim

Termitomyces $\mathrm{sp}$.

Family Marasmiaceae

Crinipellis sp.

Marasmiellus spp.

2

Marasmius crinis-equi F. Muell. 18

ex Kalchbr.

Marasmius rotalis Berk. \& $\quad$ - $\quad 12$

Broome

$\begin{array}{lll}\text { Marasmius spp. } & 2 & 20\end{array}$

Mycetinis sp. 3

Family Mycenaceae

Mycena minya Grgur. $\quad$ - $\quad 6$

Mycena spp. $\quad 1 \quad 5$

Family Psathyrellaceae

$\begin{array}{lll}\text { Coprinellus spp. } & 2 & 4\end{array}$

Psathyrella sp. $\quad 1$

Family Schizophyllaceae

Schizophyllum commune Fr. $\quad$ - $\quad 23$

Order Boletales

Family Tricholomataceae

Leucopaxillus sp.

Family Boletaceae

Boletus sp.

Xerocomus sp.

Family Sclerodermataceae

Scleroderma sp.

Order Cantharellales

Family Cantharellaceae

Cantharellus spp. $\quad 1 \quad 1$

Family Clavulinaceae

Clavulina leveillei (Sacc.) - 3

Overeem

Order Dacrymycetales

Family Dacrymycetaceae

Dacryopinax

spathularia -

15

(Schwein.) G.W. Martin

Order Polyporales 
Family Polyporaceae

Earliella scabrosa (Pers.) Gilb. 1

\& Ryvarden

Favolus alveolaris (DC.) Quél. - $\quad 8$

$\begin{array}{llll}\text { Microporus xanthopus (Fr.) - } & 7\end{array}$

Kuntze

Nigroporus vinosus (Berk.) - 13

Murrill

Polyporus tenuiculus (P. Beauv.) - $\quad 1$

Fr.

$\begin{array}{lll}\text { Polyporus spp. } & 9 & 9\end{array}$

Trametes pubescens (Schumach.) - 2

Pilát

Trametes sp $1-1$

Trichaptum brastagii (Corner) T. $\quad-\quad 8$

Hatt.

Trichaptum $\mathrm{sp}$. $\quad$ - 2

Family Ganodermaceae
Amauroderma rude (Berk.) -

Torrend

Amauroderma sp. $\quad-\quad \begin{array}{lll}- & 1\end{array}$

Ganoderma lucidum (Curtis) P. 2 -

Ganoderma spp. $\quad 9 \quad 4$

Order Russulales

Family Hericiaceae

$\begin{array}{lll}\text { Hericium } \mathrm{sp.} & 8 & 7\end{array}$

Family Stereaceae

Stereum lobatum (Kunze ex Fr.) $6 \quad$ -

Fr.

Family Russulaceae

Russula sp. $\quad$ - $\quad 3$

Order Tremellales

Family Tremellaceae

Tremella fuciformis Berk. $\quad$ - 3

\begin{tabular}{llll}
\hline Unknown & & & \\
& Unknown species 1 & 1 & - \\
& Unknown species 2 & - & 2 \\
\hline Total specimens & & 142 & 173 \\
\hline
\end{tabular}

The total number of macrofungi species collected on trail A (former Vietnamese refugee camp area) were 27 species with 173 individual specimens. On the other hand, trail B (behind the dorm of UMT Bidong Island Research Station) provided 39 species with 142 individual specimens. Both trails contained macrofungql species from family Polyporaceae, Cantharellaceae, Ganodermaceae, Marasmiaceae, Mycenaceae, Psathyrellaceae and Xylariaceae with family Polyporaceae having the most diverse species among other families with 13 species out of 65 macrofungi species (Figure 4). The second highest number of species were from family of Marasmiaceae ( $n=9$ species). This was followed by Ganodermataceae, Mycenaceae and Psathyrellaceae. Species from family Polyporaceae are wood-inhibiting macrofungi that are abundant and diverse in this study because of the diversity of substrates mainly woods available for them to grow on (Bolhassan et al., 2013). A previous study by Pesiu et al. (2016) reported that there were a total of 102 living tree species in Bidong Island which indicated that there were diverse types of wood substrates including living trees and decaying woods. This could increase the diversity and abundance of species from order Polyporales as these species have a larger variety of host to grow on. 


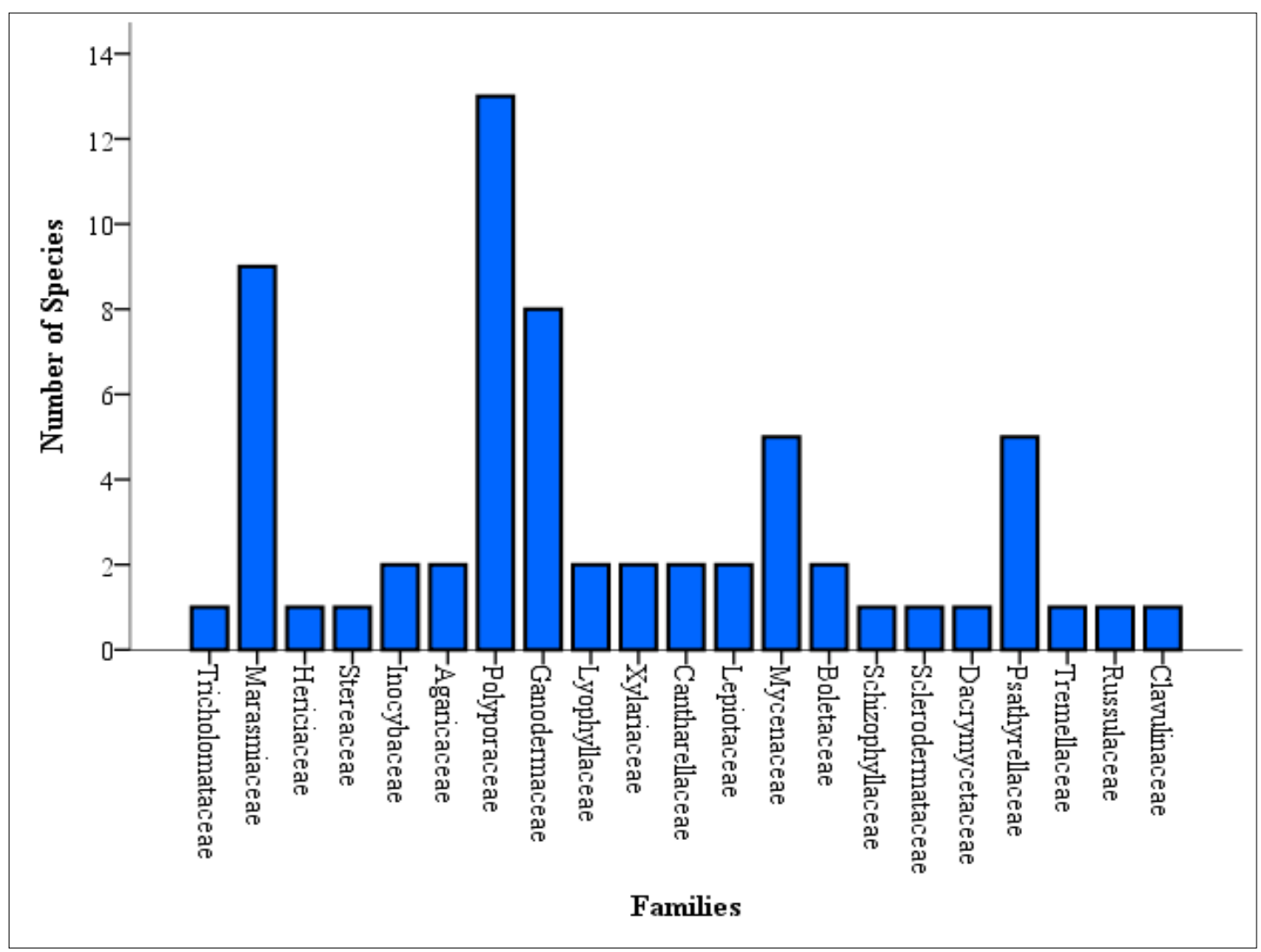

Figure 4: Number of species and families of macrofungi found in Pulau Bidong

In 2014, Aziz (unpublished thesis) recorded 16 species, and in 2015 Razak (unpublished thesis) recorded 45 species which included all of 16 species found by Aziz (2014). In addition, the study by Razak recorded 29 new species. The comparison of species composition between the previous study by Razak (2015) with the current study was made (Figure 5). An additional 56 new species were found in the current study with 9 similar macrofungal species recorded in both studies. The current study recorded similar common species from family of Agaricaceae, Ganodermaceae and Polyporaceae.
The dominant family with the most diverse species recorded in this study was similar to the previous study by Razak (2015) which was family Polyporaceae (Figure 4). In 2015, 22 species from the family Polyporaceae were recorded while in the current study 13 species were recorded. New species recorded in the current study were from family Cantharellaceae, Clavulinaceae, Dacrymycetaceae, Hericiaceae, Inocybaceae, Lepiotaceae, Lyophyllaceae, Mycenaceae, Psathyrellaceae, Schizophyllaceae, Stereaceae, Tremellaceae and Tricholomataceae. Overall, the total accumulated macrofungi species according to the studies from 2014, 2015 and 2016 in Bidong Island were 88 species. 


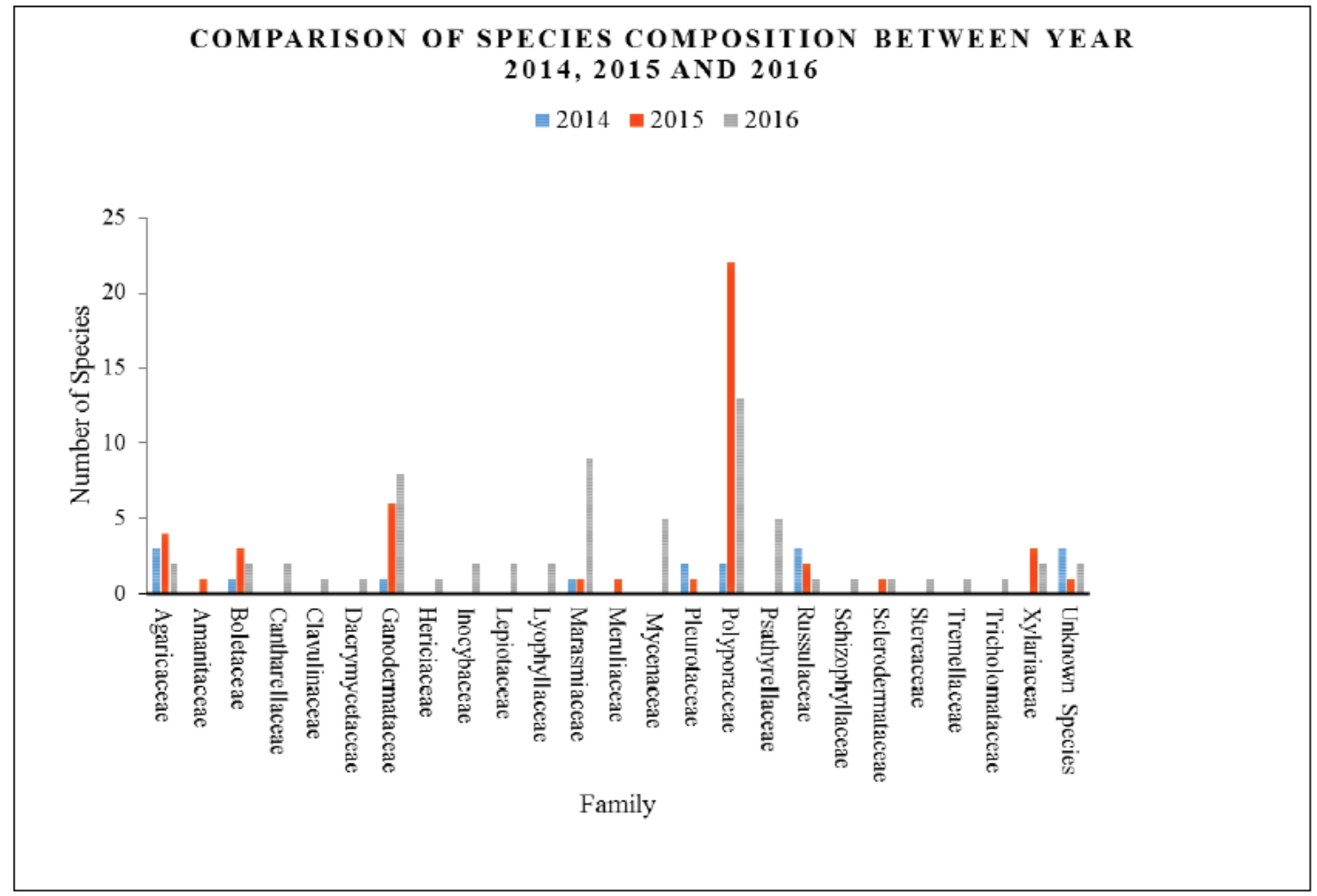

Figure 5: Species composition for 2014, 2015 and 2016

There were two types of indexes used which were Shannon diversity index and Simpson diversity index. Table 2 shows the values generated when diversity index was calculated using the data obtained. The diversity by Shannon index showed a high diversity on trail B. An index value of 4.00 indicates a very high diversity and the diversity decreases with the decrease in diversity index value, with 0 indicating zero diversity. However, Simpson diversity index for trail A was 0.90 and Trail B 0.94 (Table 2). Based on the values generated by Simpson diversity index, both trails showed high diversity. Simpson diversity index value of 1.00 indicates infinite diversity and the diversity decreases with the decrease in diversity index value, with 0 indicating zero diversity. The evenness based on Shannon index of both trails showed that not all species were evenly distributed with 0.54 for trail A and 0.59 for trail B (Table 4.2). The Shannon and Simpson Diversity Index generated indicated that trail B had high diversity of 3.14 that nearly reached 4.00 and 0.94 that nearly reached 1.00 respectively. The high diversity on trail B could be due to its longer distance, creating a higher chance of discovering higher number of macrofungi species. The environmental condition mainly the humidity and temperature of the surrounding for trail B was more favourable for macrofungi to grow. Trail B was widely covered with trees or shaded and the floor was filled with leaf litters consisting of diverse substrates mainly living and dead dipterocarps trees (Pesiu et al., 2016). These encouraged macrofungi on trail B to grow, thus causing the high diversity on trail B. A study by Karun \& Sridhar (2016) reported that the high diversity of macrofungi could be due to the occurrence of suitable abiotic conditions such as moisture or temperature and deposition of substrates on the forest floor mainly wood and leaf litters. This could be due to the accumulated litters on the floor providing important lignocellulose materials that favour the growth of macrofungi. 
Table 2: Table of diversity index

\begin{tabular}{lcc}
\hline \multicolumn{1}{c}{ Title } & Trail A & Trail B \\
\multicolumn{1}{l}{ Trails } & & \\
\hline Number of Species & 27 & 39 \\
Individuals & 142 & 173 \\
Shannon Index of Diversity (H) & 2.67 & 3.14 \\
Simpson Index of Diversity (1-D) & 0.90 & 0.94 \\
Evenness (Shannon Index) & 0.54 & 0.59 \\
\hline
\end{tabular}

The rarefaction curve generated using Paleontological Statistics (PAST) and ECOSIM software for both trails indicated that there would be an increase in the number of species if there was an increase in sampling efforts. This is because both trails generated curves that had not reached the asymptotes (Figure 6). The rarefaction curve in this study indicated that there would be more species discovered with the increase in sampling efforts for both trails. This could be due to limited sampling trips and sampling period. The number of species might increase if there were more sampling trips involved as the discovery rate would increase with diversity when more trips were involved until the curve reached asymptotes. It is also expected that different species may be discovered on different trips due to varied environmental conditions depending on the weather and time for every trip (Ujang, 2002). Thus, these may encourage different kinds of macrofungi to grow depending on their preferences (Kutszegi et al., 2015).

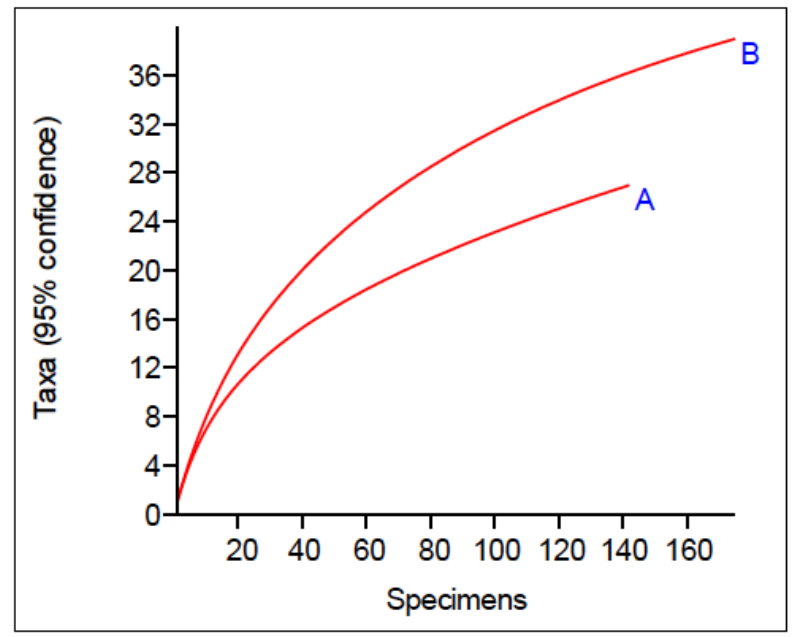

Figure 6: Rarefaction curve for trail A and trail B

There were six types of substrates based on the macrofungi species found on both trail A and trail B in Pulau Bidong, which included soil, decayed branches, decayed trunks, termite mounds, decayed leaves and living trees (Figure 7). From the specimens collected, the most abundant substrates based on the macrofungi species found were decaying plants materials including decayed branches, decayed trunks and decayed leaves. Decayed branches made up the highest number of substrates for the macrofungi species found. In addition, 30 species out of 65 species were found growing on the dominant substrates which were decaying branches. This could be due to a variety of forest community structures that wete available for macrofungi to grow on such as various plants species and habitat condition (Moore et al, 2001). The varieties of plant species including a variety of tree composition with varied ages, nutrient compositions within the decaying plant materials and sizes of the substrates could encourage wide ranges of macrofungi to develop and grow. Pesiu et al. (2016) reported that the composition of trees in Pulau Bidong consisted of 102 species with diameter at breast height (DBH) of between $5 \mathrm{~cm}$ to $44.99 \mathrm{~cm}$ and the height of the trees varied between $3 \mathrm{~m}$ to $22.99 \mathrm{~m}$. This shows that the variety of tree species with different sizes could produce wide ranges of substrates in the island. A study in Redang Island of Malaysia also showed similar results on the macrofungi substrates with the dominant 
substrates being decaying plant materials including branches, trunks, roots, twigs and fruits (Zainuddin et al., 2010). On the other hand, a study in India also showed that the major substrates preferred were wood litters that included barks, twigs and woods (Karun \& Sridhar, 2016). Thus, it was proven that the common substrates for macrofungi were decaying plant materials.

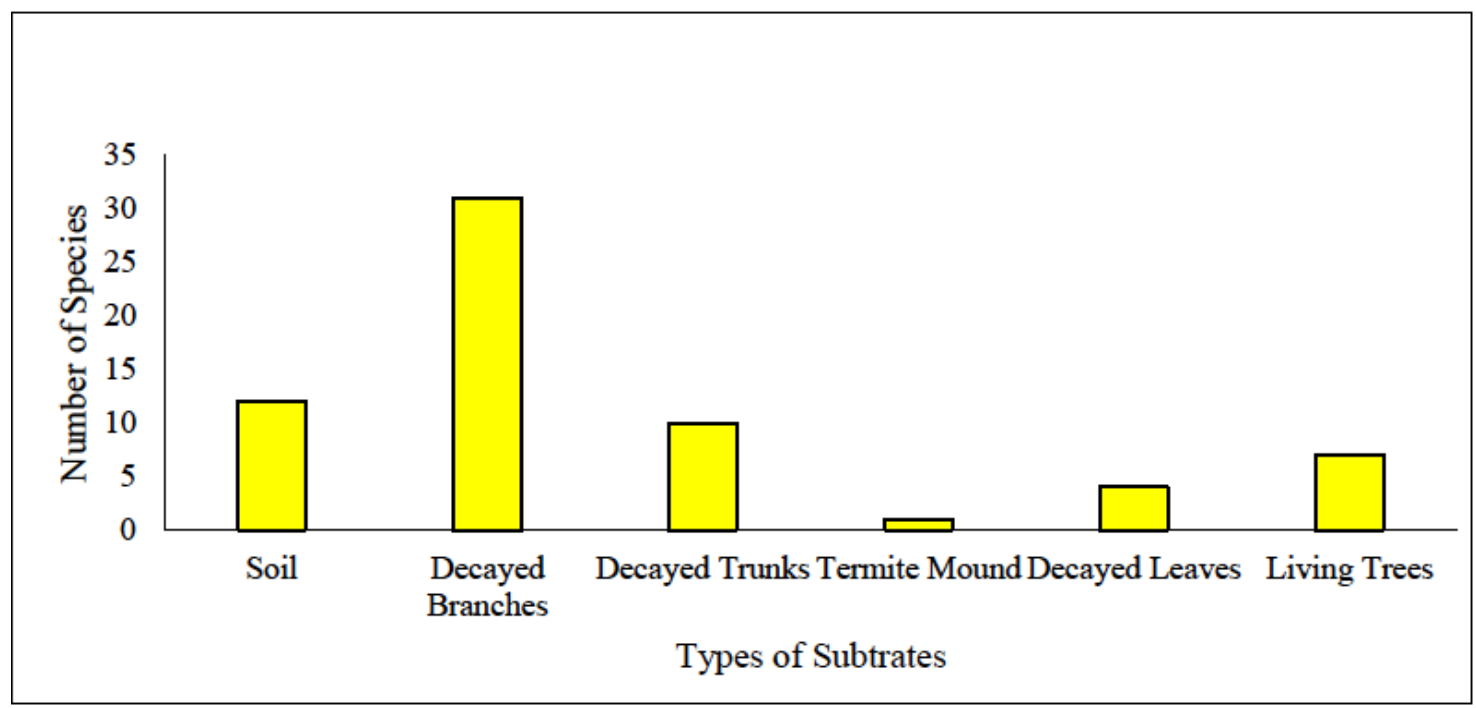

Figure 7: Types of substrates with the number of species

Trail A had an average humidity of $78.84 \%$ at the location where 173 individual specimens were found while trail B had an average humidity of $84.03 \%$ (Table 3 ). Trail B had higher average humidity compared to trail
A. Also, the average temperature for trail A and trail B did not differ much. Higher light intensity was recorded at Trail A compared to trail B.

Table 3: Average environmental parameters for trail A and trail B

\begin{tabular}{ccc}
\hline Average & \multicolumn{3}{c}{ Trails } \\
\cline { 2 - 3 } & Trail A & Trail B \\
\hline Humidity (\%) & 78.84 & 84.03 \\
Temperature $\left({ }^{\circ} \mathrm{C}\right)$ & 29.14 & 29.93 \\
Light Intensity $(\mathrm{cd})$ & 1.67 & 0.68 \\
\hline
\end{tabular}

This study may provide a baseline information for assessment of diversity and health of the forest in Pulau Bidong. Besides that, it can contribute towards conservation efforts on ecosystem health and forest resources in island ecosystems. As there were some

\section{References}

Abdullah, N., Vikineswary, S., Yusoff, M. \& Desjardin, D.E. (2005) Higher fungi of Northeast Langkawi. Malaysian Journal of Science, 24, 95-102.

Adanan, N.A., Basari, N., Rosmidi, F.H., Pesiu, E. \& Abdullah, M.T. (2016) Preliminary studies on bees at Pulau Bidong and Pulau Perhentian, Terengganu. Journal of Sustainability Science and Management, $1,36-40$.

Aziz, S.A.A. (2014) Identification of macrofungi species at Bidong Island, Terengganu. B. Sc. Thesis. Universiti Malaysia Terengganu. limitations such as limited sampling trips and overlooked samples in this study, it is recommended that sampling efforts be increased in future studies by having longer sampling periods and frequent visits for better outcomes.

Bolhassan, M.H. (2013) Diversity of Polyporales in the Malay Peninsular and the application of Ganoderma australe (fr.) Pat. in biopulping of empty fruit bunches of Elaeis guineensis. Ph.D. dissertation. University Of Malaya.

Karun, N.C. \& Sridhar, K.R. (2016) Spatial and temporal diversity of macrofungi in the

Western Ghats forests of India. Applied Ecology and Environmental Research, 14(2), 1-21.

Kendrick, B. (2002) The Fifth Kingdom. $3^{\text {rd }}$ ed. Mycologue Publications, United States. 386 pp. 
Kuthubutheen, A.J. (1981) Notes on the macrofungi of Langkawi. Malayan Nature Journal, 34(3), 123-13.

Kutszegi, G., Siller, I., Dima, B., Takács, K., Merényi, Z.S., Varga, T., Turcsányi, G., Bidló, A., Ódor, P. (2015) Drivers of macrofungal species composition in temperate forests, West Hungary: functional groups compared. Fungal Ecology, 17, 69-83.

Mohammad, A., Yee, L. S., \& Kasran, A. K. (2019). Macrofungi of Tasik Kenyir. In: Abdullah, M.T., Mohammad, A., Nor Zalipah, M., Safiih Lola, M. (Eds). Greater Kenyir Landscapes. Cham: Springer. pp. 67-74

Moore, D., Nauta, M.M., Evans, S.E. \& Rotheroe, M. (2001) Fungal conservation: issues and solutions. In: Molina, R., Pilz, D., Smith, J., Dunham, S., Dreisbach, T., O'dell, T. \& Castellano, M. (Eds.) Conservation And Management Of Forest Fungi In The Pacific Northwestern United States: An Integrated Ecosystem Approach. British Mycological Society Symposium. United Kingdom: Cambridge University Press. pp. 19-63.

Oberwinkler, F. (2012) Evolutionary trends in Basidiomycota. Stapfia, 96, 45-104.
Pesiu, E., Abdullah, M.T., Salim, J. \& Salam, M.R. (2016) Tree species composition in Pulau Bidong and Pulau Redang. Journal of Sustainability Science and Management, 1, 48-60.

Rayner, R.W., Watling, R. \& Turnbull, E. (1969) Flora of British Fungi: Colour Identification Chart. United Kingdom: Her Majesty, The Stationery Office. 189 pp.

Razak, F.A.A. (2015) Macrofungi flora in Bidong Island, Terengganu. B. Sc. Thesis. Universiti Malaysia Terengganu.

Staples, R. (2007) Fungal cannons: Explosive spore discharge in the Ascomycota. Journal Table of Contents, 276(1), 12-18.

Ujang, S., Jones, E.B.G. \& Watling, R. (2002) The distribution of wood-inhabiting fungi in Peninsular Malaysia. Journal of Tropical Forest Science, 14(4), 433-440.

Zainuddin, N., Alias, S.A., Kin, T.B., See, L.S. \& Twu, C.H. (2010) Macrofungi of Pulau Redang, Terengganu and Pulau Aur, Johor in the South China Sea. Journal of Science and Technology in the Tropics, 6, 120-125. 